\title{
Florigen and anti-florigen - a systemic mechanism for coordinating growth and termination in flowering plants
}

\author{
Eliezer Lifschitz $^{1}{ }^{*}$, Brian G. Ayre ${ }^{2}$ and Yuval Eshed ${ }^{3}$ \\ Department of Biology, Technion - Israel Institute of Technology, Haifa, Israel \\ ${ }^{2}$ Department of Biological Sciences, University of North Texas, Denton, TX, USA \\ ${ }^{3}$ Department of Plant Sciences, Weizmann Institute of Science, Rehovot, Israel
}

\section{Edited by:}

George Coupland, Max Planck

Society, Germany

\section{Reviewed by:}

Steve M. Mount, University of

Maryland, College Park, USA

Rita Sharma, Jawaharlal Nehru

University, India

\section{${ }^{*}$ Correspondence:}

Eliezer Lifschitz, Department of

Biology, Technion - Israel Institute of

Technology, Technion City,

Haifa 3200003, Israel

e-mail: lifs@tx.technion.ac.il
Genetic studies in Arabidopsis established FLOWERING LOCUS T (FT) as a key flowerpromoting gene in photoperiodic systems. Grafting experiments established unequivocal one-to-one relations between SINGLE FLOWER TRUSS (SFT), a tomato homolog of FT, and the hypothetical florigen, in all flowering plants. Additional studies of SFT and SELF PRUNING (SP, homolog of TFL 1), two antagonistic genes regulating the architecture of the sympodial shoot system, have suggested that transition to flowering in the dayneutral and perennial tomato is synonymous with "termination." Dosage manipulation of its endogenous and mobile, graft-transmissible levels demonstrated that florigen regulates termination and transition to flowering in an $S P$-dependent manner and, by the same token, that high florigen levels induce growth arrest and termination in meristems across the tomato shoot system. It was thus proposed that growth balances, and consequently the patterning of the shoot systems in all plants, are mediated by endogenous, meristemspecific dynamic SFT/SP ratios and that shifts to termination by changing SFT/SP ratios are triggered by the imported florigen, the mobile form of SFT. Florigen is a universal plant growth hormone inherently checked by a complementary antagonistic systemic system. Thus, an examination of the endogenous functions of FT-like genes, or of the systemic roles of the mobile florigen in any plant species, that fails to pay careful attention to the balancing antagonistic systems, or to consider its functions in day-neutral or perennial plants, would be incomplete.

Keywords: flowering time, florigen, mobile growth terminators, SFT/SP regulatory hierarchy, shoot architecture, sympodial tomato

\section{EVOLUTION OF THE FLORIGEN EXPERIMENTAL PLATFORM AND THE SFT/SP REGULATORY PARADIGM IN TOMATO}

The florigen hypothesis emerged from elegant grafting experiments in photoperiod-sensitive plants (Chailakhyan, 1936a,b). Extensive experiments in the following 40 years, using a variety of photoperiod-sensitive plants, supported the florigen paradigm and established its core physiological parameters. These were critically evaluated in the superb compendium directed by Zeevaart (1976) and can be summarized as follows: (A) Changing light regimes induces systemic florigenic signals in cotyledons and leaves, which are transported, primarily via the phloem, to the apical meristems, where they induce transition to flowering. (B) While the primary environmental inductive signals may vary, the final stimulus is universal and thus, can be transmitted between species; long-day and short-day plants respond to the same florigenic signal. (C) The florigenic stimulus and the flowering response are quantitative. (D) The florigenic stimulus is balanced by systemic anti-florigenic agents.

In the domains of classic plant physiology, florigen was considered the ultimate and sometimes the sole agent for flowering. The classification of florigen as a systemic stimulant and the prevailing expectation that it is a metabolic product analogous to auxin and other plant hormones, laid the foundation for decades of futile hunts. Florigen took on mythical proportions, and became the "Holy Grail" of plant biology: extensively sought after, but never found (Bernier, 1988; Zeevaart, 2006). With the adoption of genetic and molecular approaches in plant biology, pioneering screens for flowering genes identified five discrete flowering pathways (Koornneef et al., 1991; Simpson and Dean, 2002; Turck et al., 2008). The discovery of seemingly linear, and only partially overlapping genetic pathways, gave rise to postflorigenic interpretations of floral induction, in which florigen had no place. However, further genetic analyses in Arabidopsis showed that while several independent flowering inducing pathways exist, the final outputs of all pathways converge on a small number of flowering promoting genes, one notable one being FLOWERING LOCUS T (FT; Samach et al., 2000; Putterill et al., 2004).

Our encounter with the florigen odyssey was stirred by the analysis of SELF-PRUNING (SP) in tomato (Yeager, 1927; MacArthur, 1932; Pnueli et al., 1998), a perennial, day-neutral bush with a stereotypical sympodial growth habit (Figure 1). The upright growth of tomato is manifested by an apparent linear shoot consisting of consecutive sympodial units (SU), each forming three leaves before terminating in a compound inflorescence. Mutant $s p$ 
A
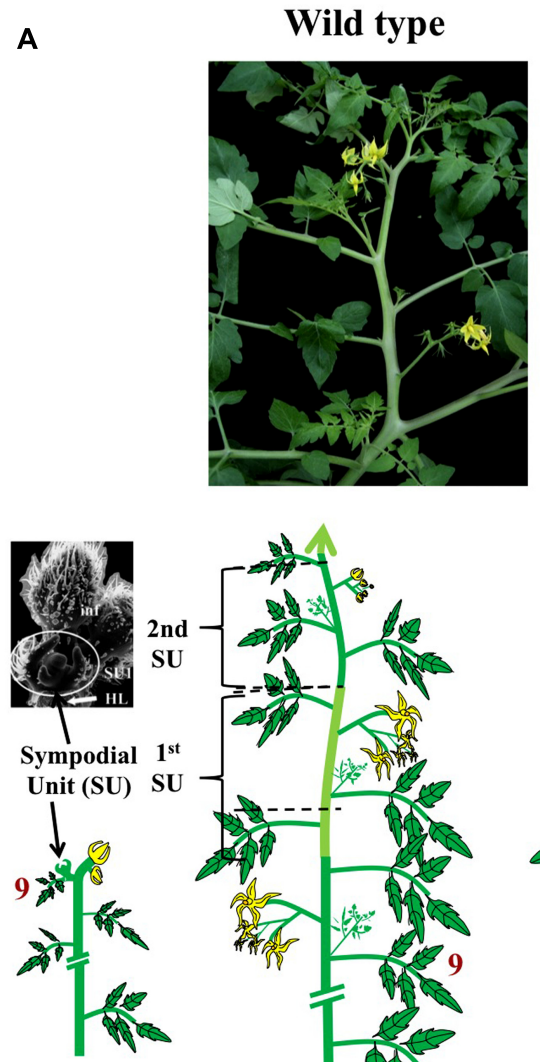

Primary

Flowering

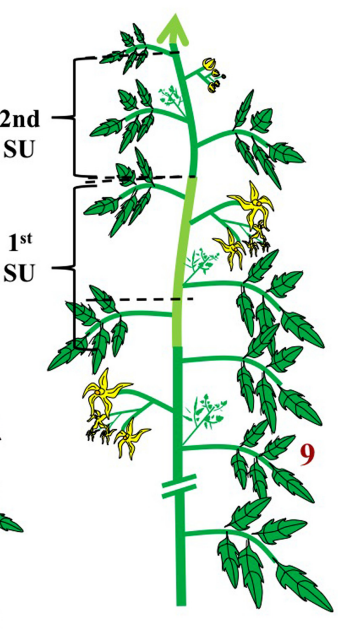

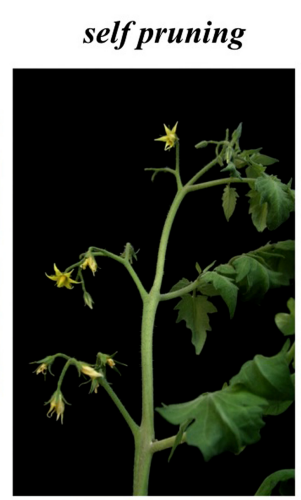

\section{single flower truss}
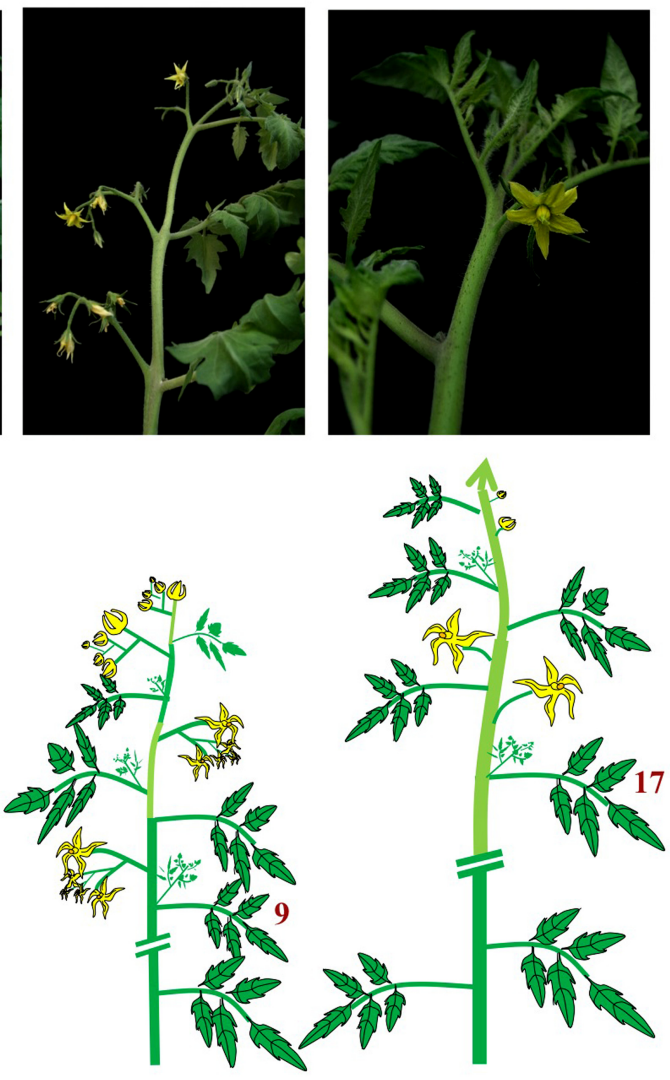

B

\begin{tabular}{|l|l|l|l|l|l|l|}
\hline Genotype & Wild type & $\begin{array}{c}\text { self } \\
\text { pruning } \\
(\mathbf{s p})\end{array}$ & $\begin{array}{c}\text { single flower } \\
\text { truss (sft) }\end{array}$ & 35S:SFT & sp 35S:SFT & 35S:SP \\
\hline $\begin{array}{l}\text { Primary } \\
\text { termination }\end{array}$ & $\begin{array}{l}\text { Regular 7-10 } \\
\text { leaves }\end{array}$ & Regular & Delayed & Accelerated & Accelerated & Delayed \\
\hline $\begin{array}{l}\text { Sympodial } \\
\text { termination }\end{array}$ & $\begin{array}{l}\text { Regular - every } \\
3 \text { leaves }\end{array}$ & Accelerated & Disrupted & Regular & Disrupted & Delayed \\
\hline
\end{tabular}

\section{FIGURE 1 | Genetic regulation of shoot architecture in sympodial} tomato. (A) Live images (top) and the corresponding schematic illustrations (bottom) of the wild type, self-pruning and single flower truss shoots of tomato. The primary shoot of wild type tomato (left) is terminated by the first inflorescence relatively early, after about 8-12 leaves. The first termination event activates the sympodial cycle (bottom left). In sympodial plants, the apparent main shoot consists of a reiterated array of sympodial units (SU). Each SU arises from the most proximal axillary meristems, and, depending on the prior regulated termination of the preceding unit, consists, in the case of tomato, of three vegetative nodes and a terminal inflorescence. The tomato inflorescence itself is a sympodial structure in which vegetative nodes are suppressed, intercalary leaves removed and each SU is terminated by a single flower. Similarly, the complexity of SUs may vary between systems being reduced to two vegetative nodes in cotton or one in Petunia. The "determinate" shoot of the self-pruning mutant plants (middle). A mutant $s p$ gene accelerates the termination of SUs but does not change the rules of the sympodial habit as such. The result is a progressive reduction in the number of vegetative nodes between inflorescences in a pattern that depends on light intensity and genetic background. The indeterminate growth in sft mutant plants (right). Unlike $S P$, the SFT gene targets, among its other pleiotropic functions, the sympodial branching pattern proper. In sft, primary termination is delayed and the terminating organ forms one flower and then proceeds as a vegetative shoot with irregular intercalary flowers. And since the formation of a new SU depends on the termination of the former one, the incomplete termination in sft results in the delayed formation, or complete suppression of the sympodial buds. Axillary buds release form leaves of the primary shoot or vegetative inflorescence follow the same path to generate the sft shoot system. Note that no full-proof loss-of-function allele of SFT is available and that the number of leaves formed by the vegetative inflorescence depends on the genetic background, and on the integral light doses. (B) Dose-dependent regulation of primary and sympodial termination by the SFT and SP genes. The SFT/SP paradigm is derived from the contrasting, but at the same time mutually dependent effects, of the loss and gain of functions of the two CETS genes. For examples: sft disrupts the sympodial habit but is epistatic to $s p$ in the double mutant combination. The effects of SFT on the sympodial habit, stem growth, and leaf complexity depend on the dose of $S P$ and in general the morphogenetic effects of mutant SP depend on a functional SFT. 
plants form progressively shorter SUs, until the shoots terminate in two successive inflorescences (Figure 1). Therefore, in wild type (WT) and in sp plants, flowering is synonymous with termination (i.e., termination of the SU), with $S P$ functioning as an anti-terminator, maintaining vegetative growth (i.e., production of leaves) in each SU. This basic understanding inspired the appreciation that "termination" is the prime function of florigen. In retrospect, $S P$ was the first annotated flowering antagonist gene and the introduction of the recessive $s p$ gene into tomato cultivars 70 years ago, facilitated mechanical harvesting, industrial production, and the irreversible flooding of the world with ketchup.

The identification of CENTRORADIALIS ( $\underline{C E N)}$ of Antirrhinum majus and TFL1 of Arabidopsis as homologous genes that maintain the indeterminate habit of the shoot apical meristems (SAMs) of monopodial plants (Bradley et al., 1996, 1997), conceptually and practically facilitated the cloning of $\underline{S} P$ as the third member in the CETS gene family (Pnueli et al., 1998). These findings were followed by the cloning of FT, another CETS-family member (Kardailsky et al., 1999; Kobayashi et al., 1999). Then, critical evidence was obtained that the proteins produced by $S P$ of tomato and FT of Arabidopsis share binding partners (Pnueli et al., 2001) and that the tomato homolog of FT is the late-flowering SFT gene (Lifschitz et al., 2006). In contrast to SP, inactivation of SFT suppresses termination, consequently promoting the formation of an indeterminate vegetative inflorescence, typically consisting of one or a few flowers intervened by leaves. Furthermore, because the release of new SUs is linked to termination, sft concomitantly suppresses the timely formation of SUs (Figure 1). By regulating the periodicity of vegetative-reproductive switches, $S P$ and SFT dictate the overall architecture of the shoot system.

Thus, genes promoting termination and flowering in monopodial, indeterminate, and photoperiod-sensitive plants congregate under a single molecular umbrella together with genes regulating the growth/termination cycling in perennial day-neutral plants. The evidence for a common molecular flower-promoting denominator in such diverged systems, and the fact that of all genes assigned to the multiple flowering pathways, only FT/SFT were not transcription factors, expedited our attempts to duplicate the grafting experiments that evoked the florigen hypothesis. Instead of exploiting donors induced by photoperiodic signals, we used SFT-overexpressing tomato plants, and instead of receptors/testers growing under non-permissive day-length conditions, we used tomato lines defective in flowering genes. These experiments showed that SFT generates graft-transmissible signals that substitute for external and internal flowering signals and established, for the first time, an unequivocal one-to-one relation between the elusive florigen and a single Mendelian gene (Figure 2; Lifschitz etal., 2006). The requirements for universality were satisfied by the mobile florigen-complementing flowering mutants independent of light regimes and were further substantiated by demonstrating that a tomato donor of SFT rescued flowering of the classic Maryland Mammoth tobacco grown under non-permissive conditions (Garner and Allard, 1920; Yang et al., 2007). The genetic evidence for the florigenic signal being a protein, and not RNA, is convincing and amply discussed

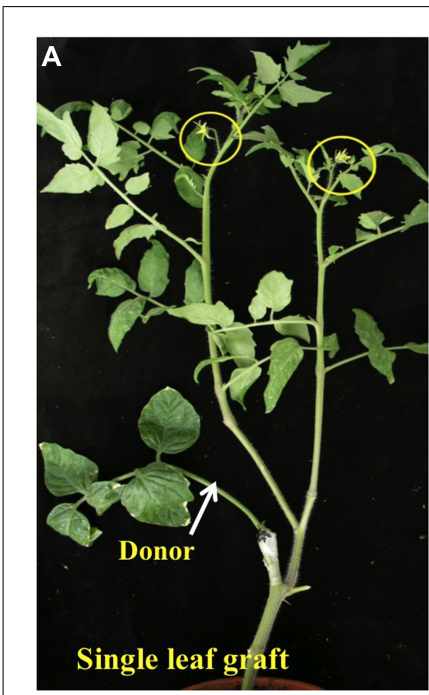

$S P$ uf sft receptor

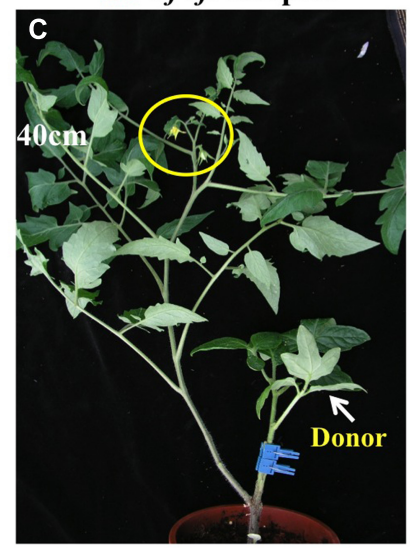

D

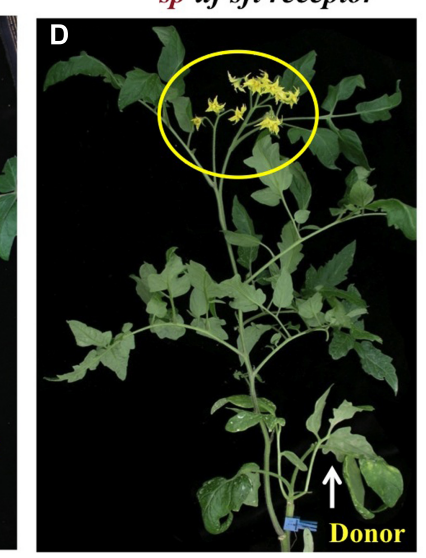

FIGURE 2 | Systemic delivery of Florigen and its local check by SP. (A) A single leaf donor can stimulate flowering in an ever-vegetative uf sft recipient. (B) A Tomato florigen donor induces flowering in a long-day grown MM tobacco plant (Lifschitz et al., 2006). (C,D) Quantitative amelioration of Florigen impact - the regular response of ever-vegetative uf sft recipient shoot (C) is greatly enhanced in the absence of SP (D).

(Lifschitz et al., 2006; Kobayashi and Weigel, 2007; Lin et al., 2007; Mathieu et al., 2007; Turck et al., 2008), although critical details of the systemic pathway as discussed below, are still lacking or under debate.

Gene dosage analysis and epistasis tests using loss- and gainof-function SFT and SP genes, revealed that, in addition to their effects on flowering, the two genes are involved in multiorgan pleiotropic effects, all of which can be traced to shifts in the growth-termination equilibrium. Concomitantly, grafting experiments showed that every developmental change conditioned by endogenous shifts in the SFT/SP ratios can be reproduced by elevated ratios imposed by graft-transmissible florigen (Shalit et al., 2009).

Integration of the results from complementary grafting and genetic experiments provided a new working hypothesis for the florigen world: endogenous SFT/SP ratios regulate local growthtermination equilibria in all meristems of the tomato shoot system. 
A switch from growth to maturation and termination is triggered by an organ-specific shift from a low to a high SFT/SP ratio. In its refined version, and within given thresholds, the SFT/SP paradigm specifies that the mere shift, rather than the absolute levels of its components, determines the developmental outcome. Florigen originates primarily in mature leaves, which are the best exporters of florigen, but is distributed to all organs including other developing leaves. Thus, by enhancing the maturation of acceptor leaves, florigen generates an autoregulatory systemic information system. Florigen functions as a universal growth hormone (Shalit et al., 2009; Turnbull, 2011), where its role in boosting flowering reflects its fundamental function as a modifier of growth and termination across the shoot systems. In all its roles, the florigen protein emerges as both the architectural regulator and "great communicator" of the shoot systems in flowering plants.

Below, we review the impact of the mobile florigen in the context of the SFT/SP paradigm, on development, and while many pioneering molecular details associated with the endogenous functions of FT-like genes were formulated in Arabidopsis, we use tomato as the "centre of gravity" in this review.

\section{FLORIGEN, FLOWERING PATTERNS, AND SHOOT ARCHITECTURE}

Shoot and flowering systems in plants differ in their inherent potentials to respond to environmental signals and in their innately regulated growth habits, which together dictate different adjustments of, and by, the florigen system. Comparison of the florigen systems in different species facilitates the classification of its universal versus species-specific functions; however, such a comparison is only useful when the growth habits of the examined plants are well understood. In their response to photoperiods, plants are categorized as long-day, short-day, or day-neutral plants. Species can be classified by their life cycles as annual, biennial, or perennial, each with its own adaptive florigenic system, and also by their growth habits as monopodial or sympodial. In the biennial onion, the response to floral signals depends on exposure of the bulb to a cold winter (Lee etal., 2013), whereas in the carrot, storage is built up during the first year and flowering occurs in the following summer. In short-lived perennials such as Arabis alpina, flowering is restricted to particular branches that will flower in the next year, only after exposure to inductive conditions (Wang etal., 2011). Interestingly, a short-lived perennial, or alternatively, an annual habit, is observed in populations of monkey flowers living in near-shore habitats or in more inland populations, respectively (Lowry and Willis, 2010). Polycarpic perennial bushes with multiple flowering cycles in every growing season, such as tomato, maintain a sympodial habit in all their shoots (Figure 1), whereas others, like cotton, display a blend of developmentally regulated sympodial and monopodial shoots (Mauney and Ball, 1959; McGarry and Ayre, 2012a,b). Deciduous perennials, such as apple, maintain largely sympodial branching and regulate flowering in lateral branches by a combination of endogenous and external cues (Hallé et al., 1978; Costes and Guèdon, 2012).

How are the different components of the florigen system, which includes biosynthesis, cellular compartmentalization, export, phloem transport, and targeting, adapted to regulate such diverse patterns of vegetative and reproductive cycles?

The annual monopodial and day-length-sensitive plants are best represented by Arabidopsis (Meyerowitz, 1989; Koornneef et al., 1991). The apical meristem of Arabidopsis is indeterminate throughout its life cycle and all appendages are laterals, with leaves and flowers being the only determinate organs. The annual life cycle of Arabidopsis must match the seasons, and requires a timely, and thereby inducible, transition to flowering. This occurs once during the life cycle, affects both apical and axillary apices and is manifested by a clear distinction between vegetative and reproductive phases. Accordingly, in order to serve its role in flowering, florigen may reach the primary apex only once in a lifetime, within a narrow time window. Such an initial day-length signal is mostly sufficient to activate flowering in lateral shoots (Corbesier et al., 1996).

The inducible flowering systems of annual plants, such as Arabidopsis and rice, are also regulated, in part, by internal signals, but primarily by signals generated by light quality and periodicity (Putterill et al., 2004). Central to the upstream activating program of FT-like genes in photoperiod-sensitive annual plants, is the circadian clock output transmitted by the GIGANTEA-CONSTANS (GI-CO) pathway (Suarez-Lopez et al., 2001; Mizoguchi et al., 2005). CO lacks a DNA-binding domain and is recruited to CCAAT binding sites of FT by NF-YC, a member of the trimeric CBF family (Ben-Naim et al., 2006; Wenkel et al., 2006; Kumimoto et al., 2008). The role of CO in regulating FT in day-length plants was adequately demonstrated by its contrasting effects on the FT genes of Arabidopsis and rice (Putterill et al., 1995; Hayama et al., 2003), but variations on these themes have been reported. For example, expression of tomato $C O$ failed to modify flowering time in tomato, Arabidopsis, and tobacco (Ben-Naim et al., 2006). In the short-day Pharbitis nil, the daily expression profiles of the two flowering-promoting FT paralogs are uncoupled to those of $C O$, suggesting that FT in this species might be regulated by other transcription factors (Hayama et al., 2007). Therefore, mechanistic claims based solely on expression profiles of the seasonal CO-FT module in other plants, particularly deciduous trees, should be considered with caution because, unlike in Arabidopsis and Pharbitis, such claims have not been backed by rigorous genetic tests (Ballerini and Kramer, 2011). Direct conditional repressors of FT in Arabidopsis include the MADS genes FLC and SVP (Li et al., 2008), SMZ (Mathieu et al., 2009), PIF4 (Kumar et al., 2012), epigenetic transcription regulators (Turck et al., 2007; Adrian et al., 2010), and more. But because florigen activates flowering in response to multiple environmental and endogenous signals, regulatory relations discovered in Arabidopsis should only be taken as a lead for system-specific studies.

\section{THE TOMATO SYMPODIAL SHOOT SYSTEM AND THE SFT/SP RATIO}

The sympodial system of tomato, with its polycarpic and polycyclic habits, captures the most typical features of deciduous perennials, such as grape vines and apple trees, or of perennial bushes like roses, cotton, potato, or black nightshade (Solanum nigrum; Bell, 1992). The sympodial shoot system of tomato is a 
conglomerate of three branching habits: (A) Axillary meristems of the primary shoot, which are first arrested by apical cues but are gradually released from dormancy after floral termination of the apical meristems above them (Figure 1). (B) Sympodial branching, involving an axillary meristem, hosted by the third leaf of each SU that is not subjected to apical dominance and grows out in response to signals generated by the terminating SAM, with no intervening dormancy to form the next SU (Lifschitz and Eshed, 2006). When the termination of the sympodial apex is delayed or accelerated, the formation of the next SU will be affected in a similar manner. Thus, "termination," floral transition, phyllotaxis, and branching in each SU must be coordinated in the apical bud, within a distance of 10-50 cells. (C) Regulated branching of the two remaining basal axillary meristems of each SU, from which only the second is regularly activated after being released from apical dominance. Because each SU is a replicate of its predecessor, their formation requires a self-perpetuating mechanism, with regularly cycling flowering and anti-flowering messages. Notably, the inflorescence shoot itself is a sympodium from which nodal leaves are removed and in which each flower represents the terminating organ of the previous SU (Lifschitz and Eshed, 2006; Lippman et al., 2008; Park et al., 2014; Périlleux et al., 2014).

\section{SFT/SP RATIOS IN SHOOT MERISTEMS}

In the tomato apex, while $s p$ accelerates termination of SU in a progressive, age-related manner, the primary shoots of $S P$ and $s p$ isogenic plants terminate after the same number of leaves. Conversely, overexpression of SP delays flowering of both primary and sympodial apices (Pnueli et al., 1998). A similar delay in the termination of the primary apices occurs in sft plants and results in an indeterminate inflorescence shoot with a mixture of leaves and solitary flowers that substitute for the regular compound inflorescence. Overexpression of SFT induces extreme premature termination of the primary shoot, but, in contrast to $s p$, the shoot continues to form regular SUs. When SFT is overexpressed in the $s p$ background, the sympodial system collapses, as manifested by termination of the primary apex with only 1-3 flowers, arrest of the sympodial meristems and their failure to support the formation of both a compound shoot, and formation of 1-3 leaves on the 3-4 axillary meristems of the primary shoot before terminating with a "blind" apex (Shalit et al., 2009). Termination induced by high SFT concentrations is therefore sensitive to $s p$, particularly in the SUs, which are resistant to high SFT levels under functional $S P$.

Termination and flowering in cultivated tomato are not sensitive to day length but are extremely sensitive to integral light doses (Kinet, 1977). Under low light conditions, primary flowering is delayed: first inflorescences tend to abort at their primordial stage, mature inflorescences turn partial leafy, and flowering within the SU is extended from three to five or six leaves. $s p$ plants are less sensitive to low light intensity, while $s f t$ plants are much more sensitive than their WT siblings. Overexpressors of $S F T$, in WT or sp backgrounds, are virtually insensitive to lowlight intensities. Likewise, sp accelerates sympodial of flowering in every examined recessive late-flowering background. Therefore, both $s p$ and high SFT/SP ratios can substitute for light in tomato.
In agreement with their responses to the SFT/SP ratio, the sympodial meristems are also sensitive to intermediate levels of SP and SFT. When SFT is expressed in $s p /+$ heterozygous plants, regular SUs, with two instead of three leaves, dominate the shoots (Shalit et al., 2009). But the reproductive differentiation of the shoot apex is also sensitive to dose changes in $s f t /+$ plants. Krieger et al. (2010) reported that tomato plants heterozygous for SFT and growing under wide spacing conditions, produced a much higher fruit yield as compared to other heterozygous lines, and attributed this effect to a single gene heterosis. More recently, dedicated measurements and appreciation of the fact that the heterozygous plants were also homozygous for $s p$, led to the conclusion that a dosage response to SFT, i.e., the SFT/SP ratio, tunes shoot architecture in a quantitative manner, and in particular field stands, such tuning may result in higher yields (Jiang et al., 2013).

Primary and sympodial tomato meristems are, as mentioned above, differentially sensitive to similar SFT/SP ratios. In the mature inflorescence shoots of monopodial Arabidopsis, buds in the axils of bracts terminate with a flower, with no intervening vegetative phase, while the primary SAM remains indeterminate. The SAM is "protected" from florigen activity by TFL1, as shown by tfll primary shoots, which are terminated by a flower while their flowering time is only marginally affected (Shannon and Meeks-Wagner, 1991; Alvarez et al., 1992). However, lateral shoots of $t f l 1$ plants flower after the formation of $0-2$ leaves instead of 2-5 leaves in WT. Therefore, flowering and the role of SFT/SP (FT/TFL1) ratios in both annual Arabidopsis and perennial tomato, must be considered in the framework of the two flowering systems, one for the primary shoots and the other for lateral shoots, sympodial in tomato and the regular laterals in Arabidopsis (Lifschitz and Eshed, 2006).

Importantly, all meristematic activities in the shoot systems can be terminated via elevated SFT/SP ratios. In particular, arrest of lateral expansion and secondary growth of the stems, most likely by attenuated cambial activity, typical to SFT overexpressing plants, is maintained throughout growth even if the sympodial cycle is completely recovered. Under the same SFT level, as noted above, sympodial meristems of the same shoots, maintain a regular, even if accelerated, 3-leaf cycle. The quantitative, meristem-specific impacts of the SFT/SP ratio are further illustrated through the response of the compound leaf to high SFT/SP ratios.

\section{COMPOUND LEAVES VIEW THE 1:1 RATIOS OF SFT/SP AND $s f t / s p$ AS EOUALLY INFORMATIVE}

A correlation between leaf growth and flowering has been frequently observed in many plants but has generally been attributed to secondary effects of flowering. Our results implied that transition to flowering and reduced leaf-growth represent two facets of the same developmental process. The formation of a compound leaf in tomato requires the activation of lateral leaflet meristems along the primary rachis and of additional rounds of ramification along secondary leaf rachises (Hareven et al., 1996; Efroni et al., 2010). The complexity of the leaf is marginally reduced in $s p$ plants, but plants overexpressing SP, e.g., bearing a low SFT/SP ratio, show excessive activity of the plate meristem in the lamina (Shalit et al., 2009). sft leaves have excess intercalary leaflets (folioles, Molinero-Rosales et al., 2004), while leaves overexpressing 
SFT form smaller blades and lack folioles. However, when SFT was overexpressed in $s p$ plants, a dramatic reduction in complexity was observed and leaves became progressively simple (Figure 3). All these features have also been obtained via graft-transmissible florigen. Thus, both flowering and the simplification of leaves reflect a shift from growth to termination via changing SFT/SP ratios.

Simplification of the compound leaves is also effective in $s p$ plants, if the system is sensitized by other genes, such as TRIFOLIATE (TF). Mutant $t f$ (a MYB factor, Naz et al., 2013) leaves form only one pair of leaflets (Hareven et al., 1996) and $t f$ plants have enhanced apical dominance. In contrast, if $s p$ plants (high endogenous SFT/SP ratios) flower earlier and their leaves become progressively simple with the advance of flowering, mimicking $s p$ plants overexpressing SFT. Conversely, if sft leaves (low endogenous SFT/SP ratios) carry additional leaflets. However, the regular trifoliated phenotype was rescued when $s f t$ was inactivated as well, as in tf sp sft. Thus, when one of the two genes is functional, the SFT/SP ratio determines contrasting morphogenetic consequences, but as long as functional and dysfunctional SFT and $S P$ maintain a one-to-one ratio, the morphogenetic consequences are identical (Shalit et al., 2009). This indicates that the ratio of SFT to SP, and not only their actual levels, determines the morphogenetic response. Significantly, all phenotypic changes induced by modified endogenous SFT/SP ratios, were recapitulated by graft-transmitted (systemic) florigen. In addition to rescuing the regular sympodial pattern of sft plants, mobile florigen, fully complemented all other pleiotropic defects of $s f t$, i.e., the extended adaxial sepal, suppression of sympodial buds, defective sympodial patterning and the extra folioles, by leading to recovery of the correct SFT/SP ratios. Likewise, mobile florigen also substituted for high endogenous SFT, inducing the collapse of the sympodial pattern and the simplification of the leaves in sp plants, conditioning slim stems in receptor WT shoots, and stimulating leaf simplification in $t f$ plants. The mobile florigen also rescued the size and structure of defective abscission zones in the floral pedicles of mutant macrocalix and blind plants (Figure 3; Shalit et al., 2009), and the normal flowering pattern in miR156-overexpressing plants (unpublished).

Are these characteristics of the SFT/SP ratio paradigm universal or unique to tomato? Accumulating observations indicate that growth and termination in reproductive and vegetative meristems in other plants are also dictated by the ratio of SFT and SP homologs. In Arabidopsis, termination of the inflorescence by $t f l l$ is associated with simple, smaller, and more oblique leaves in long days with photoperiodic induction of FT (i.e., high FT/TFL1 ratio); all of these characteristics can be reversed when FT levels are reduced by short days, low light, cold temperatures, or their combinations (lower FT/TFL1 ratio; our observations). Suppression of flowering in the Maryland Mammoth tobacco grown under long-day conditions is associated with giant leaves. Likewise, the leaf complexity gradually declined in distal compound leaves of different plants approaching flowering, as seen in roses (Efroni et al., 2010). In maize, reduction of florigen or increase in SP-like (ZCN2) levels resulted in larger leaves, more branched tassels and, as in tomato, thicker stems (Danilevskaya et al., 2011). In cotton, vegetative shoots are monopodial, while reproductive fruiting branches are sympodial. High FT levels induced promiscuous arrest of the sympodial branches, small and lanceolate leaves, rather than deeply lobed leaves, and thinner stems (McGarry and Ayre, 2012a,c). In potato, florigen promoted the formation of tubers - which are determinate structures - at the tips of stolons (Navarro et al., 2011), while in grapes, misexpression of an SP-like gene confers a box-like architecture, instead of an inverted pear-shape architecture on Carignan fruit clusters (Fernandez et al., 2010). An FT homolog (not in the form of a mobile florigen) of Populus tremula was shown to regulate bud set and growth (Böhlenius et al., 2006). However, since Populus has two FT paralogs, with non-overlapping seasonal expression pattern (Hsu etal., 2011), it remains unknown which of the two triggers the flowering response. Finally, the significance of the SFT/SP ratio paradigm is well illustrated in the short-lived perennial A. alpina and long-lived perennial Rosaceae. In these cases, early and reoccurring flowering, small shoots, and simpler leaves are associated with suppression of their corresponding SPlike genes (Wang et al., 2011; Iwata et al., 2012; Kurokura et al., 2013).

\section{THE ANTAGONISTIC COMPONENT OF THE SFT/SP BALANCE}

Florigen and antiflorigen are equally important constituents of floral induction (Chailakhyan, 1936a,b; Zeevaart, 1976; Lang et al., 1977). The SFT/SP ratio paradigm implies that genes belonging to the CEN, TFL1, and SP branch of the CETS may function as universal antagonists for florigen. But it also implies that regulated inactivation of SFT as such, is sufficient to generate an antagonistic developmental response.

The origin of the current florigen system in flowering plants is debated. It has been proposed that florigen endows early flowering plants, having improved conductive systems and fastgrowing meristems, with faster and versatile capabilities to adapt to new habitats and respond more efficiently to different environmental signals. But because flowering is synonymous with termination and because high, unchecked florigen levels are detrimental, we speculated that the founder SP-like antagonist coevolved with florigen to alleviate its harmful effect (Shalit et al., 2009). Indeed, a thorough phylogenetic analysis (J. Bowman, in Shalit etal., 2009, and Supplementary information therein) showed that genes of the CEN/TFL1/SP branch are missing from non-flowering plants. An additional analysis confirmed these results but suggested that a duplication of an ancient MFT gene gave rise to an intermediate florigenic FT/TFL1-like gene in extant gymnosperms, while additional duplications gave rise to the FT/SFT and CEN/TFL1/SP branches of angiosperms (Karlgren et al., 2011). In contrast to the situation in extant gymnosperms, there are only five CETS in the genome of Amborella, the only known living species from the earliest branch in the angiosperm lineage (Amborella Genome Project, 2013): three being MFT-like, one a classic FT/SFT and one a classic SP/TFL1 gene.

Expression of the FT/TFL1-like (FTL) genes of gymnosperms in Arabidopsis resulted in delayed flowering, implying a function more similar to that of TFL-1 (Klintenäs et al., 2012). However, the temporal and spatial expression of PaFTL2 and PaFTL1 implied roles in late-season bud sets (Karlgren et al., 2013) and when PaFTL2, under a heat shock promoter, was expressed in Norway 

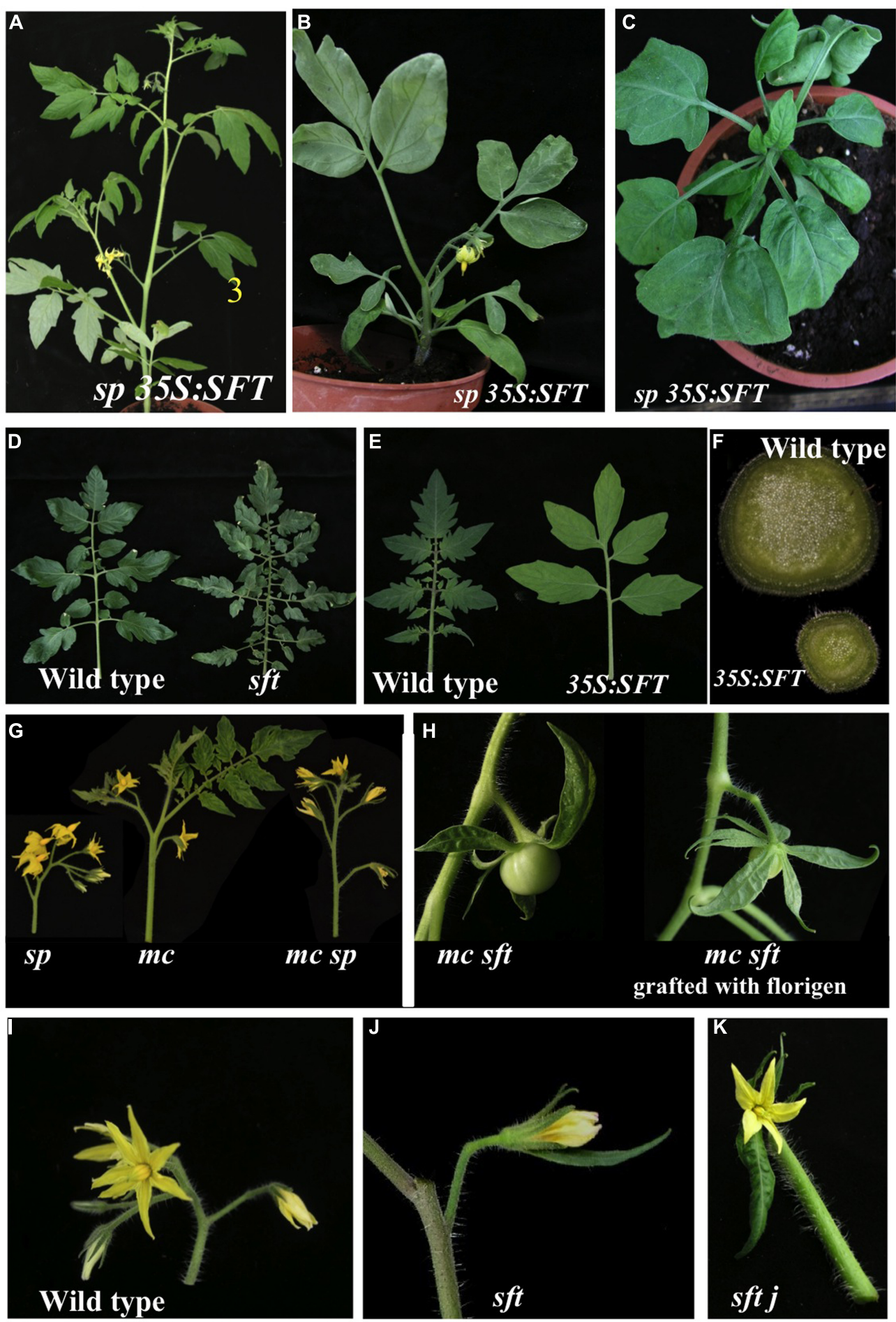

FIGURE 3 Diverse developmental systems are regulated by the SFT/SP ratio. (A) Tomato plants expressing the 35S:SFT gene flower very early but maintain normal sympodial cycling. (B,C) In the absence of SP high SFT suppresses axillary meristems (B) or even vegetative and inflorescence apical meristems. (D) sft leaves generate extra leaflets and folioles (E,F) 35S:SFT plants produce simpler leaves with entire margins. (E) High SFT induces thinner stems by arresting secondary growth. (G) Loss of MACROCALYX ( $m c$, a putative homolog of AP1) results in partially leafy inflorescence that is rescued by further loss of $S P$. In contrast, the incomplete abscission zone of $m c$ is completely eliminated in $m c$ sft but is fully restored by a mobile florigen (H). (I-K) Within the flower, sft (J) conditions the formation of a larger adaxial sepal which is greatly enhanced in jointless 1 (j1) background (K). 
spruce (Picea abies), vegetative growth transitioned to terminal bud set and growth cessation, both being steps toward dormancy and winter hardiness. Therefore, despite the observations in Arabidopsis, the FTL1 clade in gymnosperms functions more analogously to $F T$ in angiosperms by regulating patterns of perennial growth.

Much like the odyssey of florigen (Sparks et al., 2013), the course of understanding the role of the Arabidopsis TFL1 was quite convoluted before being determined as a universal antagonist of florigen. Mutations in TFL1 were initially recognized because their inflorescence shoots terminated with a single flower (Shannon and Meeks-Wagner, 1991; Alvarez et al., 1992); the gene was appropriately assigned a role in maintaining the indeterminate state of the inflorescence meristem (Ratcliffe et al., 1998, 1999). But depending on growth conditions, $t f l 1$ also displayed modestly early flowering, condensed stem nodes and smaller and more oblique leaves (Bradley et al., 1997). Overexpression of TFL1 induced late flowering, excessive branching of vegetative inflorescence shoots and expanded rosette leaves (Ratcliffe et al., 1998). But these features were always discussed in relation to floral and inflorescence meristem fate and to general regulation of the vegetative and reproductive phases, rather than in relation to floral transition proper. Any generalization with respect to flowering time was further hindered by the effects of the CEN gene of A. majus, which, unlike TFL1, did not impact flowering time when inactivated. The findings that TFL1 forms a regulatory loop with AP1 and LEAFY (Liljegren et al., 1999; Ratcliffe et al., 1999) implicated TFL1 in regulation of the "identity" of SAMs (Ratcliffe et al., 1998). But since no place was found for TFL1 along the linear day-length flowering pathways, its role in regulating flowering in Arabidopsis was largely ignored. This perspective, namely that FT is involved in flowering time, while TFL1 is involved in the distinctively separate function of meristem identity, is interestingly reflected by the complete disappearance of TFL1 from recent authoritative models and reviews on flowering (Putterill et al., 2004; Kobayashi and Weigel, 2007).

By contrast, the humble $S P$ was viewed, from the outset, as a legitimate flowering suppressor and its recessive allele as a flowering-promoting gene. This was mostly due to the original assignment of $S P$ as a regulator of the "determinate" vs. "indeterminate" modes of sympodial branching (Yeager, 1927; MacArthur, 1932). Like CEN, SP plays no role in primary flowering, yet, its inactivation induces accelerated termination without disrupting sympodial branching per se, and its overexpression delays both primary and sympodial termination. We thus regarded the gene as a legitimate component of flowering and a part of the florigen system (Pnueli et al., 1998, 2001; Lifschitz and Eshed, 2006). An important developmental consideration is that while inactivation of TFL1-like genes accelerates primary flowering in some plants, it always promotes flowering in secondary branches. Growing genetic and molecular evidence, from Arabidopsis, tomato, and other plants, provides a reasonable basis for the analysis of antagonism in the framework of the SFT/SP ratio and the endogenous and systemic functions of the CETS genes. Below, we consider this critical issue from various perspectives, while leaving several questions wide open.

\section{IT'S ALL IN THE FAMILY}

CETS genes form a small family common to all plants, with a complexity ranging from 5 in Amborella, 6 in Arabidopsis, 12 in tomato, and 25 in maize (Danilevskaya et al., 2008, 2011). CETS genes belong to a family of genes encoding mammalian phosphatidylethanolamine binding proteins (PEBP; Schoentgen et al., 1987), of which the Raf kinase inhibitor protein (RKIP), which functions via direct interaction with a 14-3-3 protein is best understood (Yeung et al., 1999; Granovsky and Rosner, 2008). CETS have been classified into three major clades (Ahn et al., 2006; Shalit et al., 2009; Karlgren et al., 2011), named after the corresponding Arabidopsis genes, TFL1, FT, and MFT (Mother of FT and TFL1). Thus far, MFT genes forming the ancestral clade, have no clear relation to flowering.

Structural analysis of RKIP revealed a small [ $\sim 180$ amino acids (AA)] globular protein with a putative binding pocket for phosphorylated ligands (Banfield et al., 1998; Serre et al., 1998). 3D analysis of the CEN protein confirmed the universal structural aspects of PEBPs, but also identified a unique, unstructured, external loop comprised of 14 AA (Banfield and Brady, 2000) common to all CETS proteins. Both the binding pocket and the external loop proved critical for the floral-promoting and floralsuppressing functions of CETS genes in Arabidopsis (Hanzawa et al., 2005; Ahn et al., 2006). A Y85H mutation, at the entrance of the putative binding pocket, or swapping the external loop of FT for that of TFL1, were each sufficient to convert FT to a flowering suppressor. However, reciprocal alterations failed to convert TFL1 to a flowering promoter. In addition, the 14-AA external loop has been shown to be conserved among FT-like genes, while those of TFL1 and MFT-like genes are widely divergent. A recent comprehensive study identified only four additional AA that were critical for converting FT to a functional TFL1 (Ho and Weigel, 2014).

Natural conversion of an FT-like gene to a floral suppressor was found in domesticated sugar beet, where a single $\mathrm{Y}$ to $\mathrm{N}$ conversion in the external loop of an FT-like paralog generated an FT antagonist (Pin et al., 2010). It will be interesting to explore the role of the authentic SP/TFL1-like gene in this species. However, as more CETS genes and their functions in different plants are reported (Meng et al., 2011; Hecht et al., 2011), it is becoming increasingly difficult to specify the number of AA alterations required to provide the external loop with a universal repressing role. Interestingly, $C E N$ and $S P$ independently antagonize flowering in Arabidopsis, but TFL1 is inert in tobacco and tomato (Amaya et al., 1999; Ahn et al., 2006). As CETS genes can counteract florigen via various mechanisms, sequence-based functional predictions can be misleading by missing the critical residues and the underlying mode of action.

An additional mechanism, generating antagonistic FT-like gene products by posttranslational modification may involve the ligand binding pockets. Nakamura etal. (2014) reported the association of phosphatydilcholine by the ligand-binding pocket of FT, suggesting the possibility other phosphorylated ligands, or a yet unknown post-translation modification, function as auto-antagonists.

In tomato, tobacco, and Arabidopsis, the natural systemic antiflorigens candidates were $S P, C E T 2 / 4$, and TFL1, respectively 
(Zeevaart, 2006), genes that, unlike FT paralogs, are preferentially expressed in the SAM. Short-range, cell-to-cell movement via plasmodesmata was shown for TFL1 in Arabidopsis (Conti and Bradley, 2007) and such movement may be a general feature of CETS genes. Nevertheless, it was recently reported that one of two TFL1-like genes in Chrysanthemum seticuspe expressed in leaves, CsAFT, suppresses flowering under inductive short-day conditions, and also induces late flowering via grafting (Higuchi et al., 2013). It is possible that in other species, other antagonistic CETS are preferentially expressed in leaves and systemically translocated to the apex. In tomato, $S P$ is predominantly expressed in the apex, but $S P 5 G$, a potential promoter of indeterminacy, is predominantly expressed in the leaves. Thus, while florigen was the first protein hormone characterized in plants, other members of the family, being functional homologs or antagonists, are also likely to function at long range.

\section{CETS PROTEINS FUNCTION AS PARTNERS IN TRANSCRIPTION COMPLEXES}

The most likely mechanism by which TFL1-like genes antagonize their flowering-promoting homologs is via formation of competitive or antagonistic transcription complexes. The first candidates for a core functional complex of CETS factors were discovered as SP-Interacting Proteins (SIP, Pnueli et al., 2001), and included the 14-3-3 adaptor proteins, SPGB (SP-associated G-box), a bZIP transcription factor homolog of FD, an SP-associated NIMA-like kinase (SPAK, Osmani et al., 1988), and a 99-amino acid-long polypeptide called SIP4. All SIPs independently interacted with the 14-3-3s and in addition, SPGB interacted with the Arabidopsis FT. SP and FT bind different 14-3-3s with different affinities and SPAK and SIP4 are, most likely, SP-specific (Pnueli et al., 2001). The plasticity, flexibility, and diversity of protein-protein interactions suggest that CETS proteins, in analogy with the 14-3-3 adaptors, function as hubs in signaling systems, with the potential to integrate a wide variety of environmental cues (Pnueli et al., 2001).

In a recent milestone discovery, Taoka et al. (2011) presented a $3 \mathrm{D}$ structure of the hetero-hexameric complex consisting of two molecules each of the rice FT homolog ( $\mathrm{Hd} 3 \mathrm{a}), 14-3-3$ and FD (OsFD1), and named it florigen activation complex (FAC). In this assembly, the 14-3-3 protein forms a bridge between $\mathrm{Hd} 3 \mathrm{a}$ and OsFD1, which otherwise do not directly interact. It was therefore postulated that the 14-3-3s are the primary intercellular receptors for mobile florigen, and that the successful interactions between bZIPs (FD clade) and FTs in yeast are actually mediated by BMH1 and $\mathrm{BMH} 2$, the two endogenous yeast 14-3-3s. But, as logical as these conjectures are, direct experimental support for both is lacking. Taoka et al. (2011) reported that other proteins, such as KANADI and WAVE-DAMPENED2 homologs, which share the SAP (Ser-Ala-Pro) domain required for binding with 14-3-3s, also recognized $\mathrm{Hd} 3 \mathrm{a}$. We identified a calmodulin binding protein of the IQD type (Abel et al., 2005), which similarly interacts with 14-3-3 proteins in a similar fashion. Ho and Weigel (2014) discovered several TCP transcription factors that differentially interact with FT and TFL1. However, different TCP binding partners were reported for the same Arabidopsis CETS proteins (Liu et al., 2012; Hiraoka et al., 2013; Ho and Weigel, 2014). In our experiments,
SP interacted with a TCP (AF175965) that was later shown to be encoded by LANCEOLATE (Ori et al., 2007) and similar TCP factors suspiciously interacted with BELL, KN, or CO. Thus, the relevance of TCB, and similarly the specificities and redundancies of the 14-3-3s to the regulatory functions of florigen require further study.

Both SFT and SP of tomato bind in yeast 14-3-3 and bZIP (SPGB) proteins, but also have their own specific binding proteins (Pnueli et al., 2001). In Arabidopsis, FT and TFL1 bind FD and FDP (Abe et al., 2005; Wigge et al., 2005), but the intercellular localization of TFL1 is questionable (Conti and Bradley, 2007; Sohn etal., 2007). The likely inference is that antagonistic proteins of the CETS family compete for a position in the same core functional complexes, or that stoichiometric relations permit the formation of two overlapping but nonidentical transcription complexes. Under either condition, the two complexes may compete for common targets or each may activate distinct antagonistic processes.

\section{TARGET COMPETITION}

One candidate target system for FT-TFL1 (SFT-SP) antagonism involves the FT-targeted AP1-SOC1-LEAFY network, which is partially regulated by TFL1 (Ratcliffe et al., 1999) and activates inflorescence and floral identity genes (Kobayashi and Weigel, 2007; Turck etal., 2008). However, the definition of AP1 as a primary target of FT and a pivotal flowering gene is problematic. Schmid et al. (2003) showed that activation of AP1 by long days is delayed until after SOC1 and FUL have responded. Yamaguchi et al. (2009) assigned the AP1 output to the meristem identity rather than to the reproductive transition. High activity of $L F Y, A P 1$, or even FUL indeed induce early flowering, but it is equally important to note that, unlike $f t$ or $s o c 1$, inactivation of LFY or AP1 has no, or only a marginal, effect on flowering time (Ruiz-García et al., 1997). Likewise, in tomato, inactivation of FALSIFLORA (FALS), the LEAFY homolog, or MACROCALYX (MC), the AP1 homolog, does not appreciably delay flowering. Significantly high SFT levels are epistatic to the "vegetative" genes fals, $m c$, and $j 1$ and to all their double combinations [J1, JOINTLESS is a MADS gene which interacts genetically with SP (Pnueli et al., 1998; Szymkowiak and Irish, 2006) and the resulting early terminating organs maintain the authentic mutant phenotypes (Shalit et al., 2009)]. While it is still unknown if constitutive overexpression of FT is epistatic to the various combinations of ap1 with the soc1 and agl24 late-flowering mutants, flowering of soc1 agl24 double mutants is delayed in short days (Li et al., 2008). Additional modifications in the current schemes for flowering transition are required to include the phenotypic interactions of $s v p$ with the double suppressor of flowering soc1-2 ful-2, as reported by Torti et al. (2012).

Additional inconsistencies in present models must be considered too. $f d p, f d$, or $f d f d p$ double-mutant Arabidopsis plants flower, where the double mutant flowering is not as late as in $f t$ and certainly not as late as in $f t$ tsf (Yamaguchi et al., 2005; Jaeger et al., 2013). Tomato $s f t$ plants also flower but, unlike with $f t$, full proof null alleles are not available. Interestingly, unlike Arabidopsis or wild tomato species, the cultivated tomato genome carries no other functional SFT homologs. 
Obviously, difficulties in reaching a coherent model arose from the ever-increasing complexity of the genetic interactions and from the lack of clarity at numerous levels: the relations between termination, inflorescence specification, and floral differentiation, between phase transition and meristem fate and between determinate and indeterminate shoots. In the indeterminate and monopodial shoots of Arabidopsis, only axillary meristems terminate to form flowers, whereas in tomato, the determinate and sympodial meristems themselves terminate and subsequently differentiate to form an inflorescence. Further understanding requires that the molecular interactions of the systemic flowering antagonists with the FT-dependent MADS target network be properly appreciated. Furthermore, to fully understand the florigen hormone and the SFT/SP regulatory hierarchy, their end users, i.e., cellular systems such as cell cycle, or cytoskeleton, not just transcription networks, should be identified.

\section{GENERAL CONSIDERATIONS RELATING TO THE SYSTEMIC PATHWAY OF FLORIGEN}

Classic grafting experiments supported the hypothesis that florigen uses the phloem track to move from leaves to the shoot apices (Zeevaart, 1962, 1976). This premise acquired molecular support when $C O$, regulated by companion cell-specific promoters, AtSUC2 from Arabidopsis and CmGAS1 of Cucumis melo, successfully induced flowering under non-permissive conditions (An et al., 2004; Ayre and Turgeon, 2004). It was also shown that $F T$ is predominantly expressed in the vasculature and that FT-derived polypeptides were detected in the phloem sap of several species. It should be noted that three phloem tracks (primary, secondary and an additional centrally located phloem) are open for the mobile florigen in Solanaceae and Cucurbitaceae (Esau, 1969), but no particular mechanistic preference has been reported. At the cellular level, most tagged FT and SFT proteins were located in the nucleus (Abe et al., 2005; Lifschitz et al., 2006), but the cytoplasmic compartments hosting the rest of the protein were not identified.

Reciprocal grafting experiments in tomato demonstrated that, in these plants, florigen moves upward and downward from SFT-overexpressing source shoots, and enters axillary buds (sinks) of the recipient stems, as was inferred from the classic analysis of florigen (Zeevaart, 1976). In a standard grafting experiment in tomato, a donor scion overexpressing $S F T$ is grafted onto a non-flowering sft uf (uniflora, Dielen et al., 2004) recipient tester with 3-4 basal leaves and their transiently dormant axillary buds. Flowering is then recorded in the out-growing laterals of the nonflowering tester (stalk). To induce flowering in this setup, florigen must translocate from the donor leaves of the scion downward to the activated axillary shoots. In a reciprocal graft, florigen is moved upward from leaves of the donor stalk to organs and apices of the recipient $s f t$ uf scion.

The cellular mechanisms regulating the intercellular migration of florigen have not yet been ascertained. As a globular protein within the size exclusion limits of plasmodesmata, florigen may enter and exit the translocation stream by a non-selective process. Recently, a newly discovered FT-interacting protein (FTIP1; Liu et al., 2012), which is associated with the endoplasmic reticulum, was suggested to mediate the exit of FT from phloem companion cells to sieve elements in Arabidopsis. However, the impact of FTIP1 on flowering is relatively mild and, more importantly, it does not bind TFL1. If the claimed specificity of FTIP1 (Liu et al., 2012) holds true, it follows that each CETS protein may require its own exit chaperon. Recently, experiments combining $F T$-mutant genes, grafting tests, and a viral expression system in Cucurbita moschata, identified mutant FT variants that cannot exit the phloem. It was suggested, that the FT protein enters the phloem translocation stream through either the selective or non-selective pathway. But active uploading from the phloem to the (unknown) target cells in the SAM (Yoo et al., 2013) requires short-distance active cell-to-cell movement, via plasmodesmata.

In Arabidopsis, FD is expressed exclusively in the SAM (Abe et al., 2005; Wigge et al., 2005) and it has therefore been rightfully accepted, that florigen must reach the apex in order to induce flowering. However, due to low levels of the traveling protein and poor resolution, direct evidence for a tagged mobile florigen reaching the target cells in the SAM proper remains to be obtained. All reported cases, in Arabidopsis, rice, or potato, recorded florigen close to, but not in, the SAM (Corbesier et al., 2007; Tamaki et al., 2007; Navarro et al., 2011). Another line of evidence, namely that FT proteins are found in the phloem sap, is required but conceptually problematic. This is because thousands of proteins have been detected in the phloem sap of several species but, with the exception of few, their functional significance in this critical compartment is poorly understood.

Interestingly, in tomato, all members of the $F D$ clade are expressed in leaves and at levels higher than SFT and in addition florigen enter leaves in which SFT is already expressed (Shalit et al., 2009). If, as we propose, the critical impact of florigen is on regulation of preexisting SFT/SP ratios in all organs, it is likely that, in some species, FT-like genes are also expressed in the SAM to maintain a local pre-flowering ratio as in tomato leaves. Indeed, we found that SFT is expressed in the primary SAM of tomato from its early inception (A. Shalit, personal communication).

Florigen was the first protein in plants demonstrated to function long range and to promote growth attenuation in all above-ground meristems, with flowering being its most visual output. The reiterated phase transition, the perennial evergreen nature of the tomato shoot system and the day-neutral flowering response require that the distribution of, and the response to florigen, be regulated on a daily basis. Mature leaves are the primary source of florigen and the removal of young tomato leaves accelerates flowering (Leopold and Lam, 1960). Florigen produced by the mature parts of the compound leaf is distributed to younger leaflets and subsequently to all organs, including leaves where SFT is already expressed. Thus, on the whole-plant level, by regulating leaf maturation, florigen controls its own levels and mode of distribution (Shalit et al., 2009).

\section{CONCLUSION}

While the core SFT/SP ratio paradigm initially provided a conceptual framework for the analysis of the growth versus termination equilibrium in the reproductive and vegetative meristems of tomato, supporting observations from other flowering systems conferred it broader and more general significance. It presents the 
best platform for further exploration of the seemingly unrelated vegetative/reproductive phenomena in several plants.

The complex interactions among CETS genes, the rapid expansion and decline in the size of this gene family, and their speciesspecific incorporation into environmental sensing-programs, have facilitated evolution of a range of flowering modes, from simple, fast-cycling annuals to complex perennials, where different branches display different autonomous flowering modes.

Transition to flowering, inflorescence differentiation, and leaf morphogenesis are quantitative and cumulative processes. The cellular mechanisms underlying the response of meristems to changing SFT/SP ratios remain unknown and it is still premature to determine the basis for growth/termination, not only vegetative/reproductive, shifts, in each meristem, or more so, in different flowering plants. Notably, the dramatic enlargement and doming of the vegetative apical meristem presents a common indication of floral transition (Bernier, 1988). Thus, SFT/SP targets must include regulators that modify the rate and orientation of cell divisions enforcing a redistribution of local signaling systems.

Adaptation of plants to different environments, an obvious consequence of domestication by humans, requires changes in flowering regulation, as well as in shoot architecture, with an unpremeditated exploitation of the SFT/SP ratio playing a seminal role in this process. As described here, these attributes were first recognized by the exploitation of a mutant SELF PRUNING gene, where accelerated termination of the WT regular sympodial cycles facilitated rapid breeding of mechanically harvested tomatoes (Rick, 1978; Pnueli et al., 1998). In retrospect, the same genetic system was exploited during the domestication, via selection of naturally occurring CETS alleles, to revolutionize a wide range of crop plants, or even to turn an exotic plant into a crop. These include, in addition to tomato, direct exploitation of changes in SP-like genes in soybeans (Tian et al., 2010), beans (Kwak et al., 2008), roses, strawberries (Iwata et al., 2012), or even in barley (Comadran et al., 2012). Likewise, mutations converting duplicated FT-like genes into floral antagonists were selected during domestication of sunflowers (Blackman et al., 2010), and sugar beet (Pin et al., 2010). Allelic variations in SFT/FT-like genes or in their upstream regulation have been reported for rice (Kojima et al., 2002; Ogiso-Tanaka et al., 2013), wheat (Bonnin et al., 2008), and potato (Kloosterman et al., 2013). Tuning of the SFT/SP ratio constitutes one of the most important processes behind crop domestication.

\section{ACKNOWLEDGMENTS}

The laboratory of Eliezer Lifschitz is supported by the Israel Science foundation (ISF; 279-11), the Russell Berrie NanoTechnology Institute and by a joint BARD grant with Brian G. Ayre (US-4535-12). Yuval Eshed's laboratory is supported by ISF (1294-10) and BARD (IS4536-12C) grants and a joined BIKURA (1552-13) grant with Eliezer Lifschitz.

\section{REFERENCES}

Abe, M., Kobayashi, Y., Yamamoto, S., Daimon, Y., Yamaguchi, A., Ikeda, Y., et al. (2005). FD, a bZIP protein mediating signals from the floral pathway integrator FT at the shoot apex. Science 309, 1052-1056. doi: 10.1126/science. 1115983
Abel, S., Savchenko, T., and Levy, M. (2005). Genome-wide comparative analysis of the IQD gene families in Arabidopsis thaliana and Oryza sativa. BMC Evol. Biol. 5:72. doi: 10.1186/1471-2148-5-72

Adrian, J., Farrona, S., Reimer, J. J., Albani, M. C., Coupland, G., and Turck, F. (2010). cis-Regulatory elements and chromatin state coordinately control temporal and spatial expression of FLOWERING LOCUS T in Arabidopsis. Plant Cell 22, 14251440. doi: $10.1105 /$ tpc.110.074682

Ahn, J. H., Miller, D., Winter, V. J., Banfield, M. J., Lee, J. H., Yoo, S. Y., et al. (2006). A divergent external loop confers antagonistic activity on floral regulators FT and TFL1. EMBO J. 25, 605-614. doi: 10.1038/sj.emboj.7600950

Alvarez, J., Guli, C. L., Yu, X. H., and Smyth, D. R. (1992). Terminal flower: a gene affecting inflorescence development in Arabidopsis thaliana. Plant J. 2, 103-116. doi: 10.1111/j.1365-313X.1992.00103.x

Amaya, I., Ratcliffe, O. J., and Bradley, D. J. (1999). Expression of CENTRORADIALIS (CEN) and CEN-like genes in tobacco reveals a conserved mechanism controlling phase change in diverse species. Plant Cell 11, 1405-1418. doi: 10.1105/tpc.11.8.1405

Amborella Genome Project. (2013). The Amborella genome and the evolution of flowering plants. Science 342:1241089. doi: 10.1126/science.1241089

An, H., Roussot, C., Suarez-Lopez, P., Corbesier, L., Vincent, C., Pineiro, M., et al. (2004). CONSTANS acts in the phloem to regulate a systemic signal that induces photoperiodic flowering of Arabidopsis. Development 131, 3615-3626. doi: 10.1242/dev.01231

Ayre, B. G., and Turgeon, R. (2004). Graft transmission of a floral stimulant derived from CONSTANS. Plant Physiol. 135, 2271-2278. doi: 10.1104/pp.104.040592

Ballerini, E. S., and Kramer, E. M. (2011). In the light of evolution: a reevaluation of conservation in the CO-FT regulon and its role in photoperiodic regulation of flowering time. Front. Plant Sci. 2:81. doi: 10.3389/fpls.2011.00081

Banfield, M. J., Barker, J. J., Perry, A. C., and Brady, R. L. (1998). Function from structure? The crystal structure of human phosphatidylethanolamine-binding protein suggests a role in membrane signal transduction. Structure 6, 1245-1254. doi: 10.1016/S0969-2126(98)00125-7

Banfield, M. J., and Brady, R. L. (2000). The structure of Antirrhinum CENTRORADIALIS protein (CEN) suggest a role as a kinase regulator. J. Mol. Biol. 297, 1159-1170. doi: 10.1006/jmbi.2000.3619

Bell, P. R. (1992). Green Plants: Their Origin and Diversity. Cambridge: Cambridge University Press.

Ben-Naim, O., Eshed, R., Parnis, A., Teper-Bamnolker, P., Shalit, A., Coupland, G., et al. (2006). The CCAAT binding factor can mediate interactions between CONSTANS-like proteins and DNA. Plant J. 46, 462-476. doi: 10.1111/j.1365313X.2006.02706.x

Bernier, G. (1988). The control of floral evocation and morphogenesis. Annu. Rev. Plant Physiol. Plant Mol. Biol. 39, 175-219. doi: 10.1146/annurev.pp.39.060188.001135

Blackman, B. K., Strasburg, J. L., Raduski, A. R., Michaels, S. D., and Rieseberg, L. H. (2010). The role of recently derived FT paralogs in sunflower domestication. Curr. Biol. 20, 629-635. doi: 10.1016/j.cub.2010.01.059

Böhlenius, H., Huang, T., Charbonnel-Campaa, L., Brunner, A. M., Jansson, S., Strauss, S. H., et al. (2006). CO/FT regulatory module controls timing of flowering and seasonal growth cessation in trees. Science 312, 1040-1043. doi: 10.1126/science. 1126038

Bonnin, I., Rousset, M., Madur, D., Sourdille, P., Dupuits, L., Brunel, D., et al. (2008). FT genome A and D polymorphisms are associated with the variation of earliness components in hexaploid wheat. Theor. Appl. Genet. 116, 383-394. doi: 10.1007/s00122-007-0676-0

Bradley, D., Carpenter, R., Copsey, L., Vincent, C., Rothstein, S., and Coen, E. (1996). Control of inflorescence architecture in Antirrhinum. Nature 379, 791-797. doi: 10.1038/379791a0

Bradley, D., Ratcliffe, O., Vincent, C., Carpenter, R., and Coen, E. (1997). Inflorescence commitment and architecture in Arabidopsis. Science 275, 80-83. doi: $10.1126 /$ science.275.5296.80

Chailakhyan, M. K. (1936a). About the mechanism of the photoperiodic response. Dokl. Akad. Nauk SSSR 1, 85-89.

Chailakhyan, M. K. (1936b). New facts supporting the hormonal theory of plant development. Dokl. Akad. Nauk SSSR 4, 77-81.

Comadran, J., Kilian, B., Russell, J., Ramsay, L., Stein, N., Ganal, M., et al. (2012). Natural variation in a homolog of Antirrhinum CENTRORADIALIS contributed to spring growth habit and environmental adaptation in cultivated barley. Nat. Genet. 44, 1388-1392. doi: 10.1038/ng.2447 
Conti, L., and Bradley, D. (2007). TERMINAL FLOWER1 is a mobile signal controlling Arabidopsis architecture. Plant Cell 19, 767-778. doi: 10.1105/tpc.106.049767

Corbesier, L., Gadisseur, I., Silvestre, G., Jacqmard, A., and Bernier, G. (1996). Design in Arabidopsis thaliana of a synchronous system of floral induction by one long day. Plant J. 9, 947-952. doi: 10.1046/j.1365-313X.1996.9060947.x

Corbesier, L., Vincent, C., Jang, S. H., Fornara, F., Fan, Q. Z., Searle, I., et al. (2007). FT protein movement contributes to long-distance signaling in floral induction of Arabidopsis. Science 316, 1030-1033. doi: 10.1126/science.1141752

Costes, E., and Guèdon, Y. (2012). Deciphering the ontogeny of a sympodial tree. Trees Struct. Funct. 26, 865-879. doi: 10.1007/s00468-011-0661-8

Danilevskaya, O. N., Meng, X., Hou, Z., Ananiev, E. V., and Simmons, C. R. (2008). A genomic and expression compendium of the expanded PEBP gene family from maize. Plant Physiol. 146, 250-264. doi: 10.1104/pp.107.109538

Danilevskaya, O. N., Meng, X., McGonigle, B., and Muszynski, M. G. (2011). Beyond flowering time: pleiotropic function of the maize flowering hormone florigen. Plant Signal. Behav. 6, 1267-1270. doi: 10.4161/psb.6.9.16423

Dielen, V., Quinet, M., Chao, J., Batoko, H., Havelange, A., and Kinet, J.-M. (2004) Uniflora, a pivotal gene that regulates floral transition and meristem identity in tomato (Lycopersicon esculentum). New Phytol. 161, 393-400. doi: 10.1046/j.14698137.2003.00937.x

Efroni, I., Eshed, Y., and Lifschitz, E. (2010). Morphogenesis of simple and compound leaves - a critical review. Plant Cell 22, 1019-1032. doi: $10.1105 /$ tpc. 109.073601

Esau, K. (1969). “The phloem,” in Handbuch der Pflanzenanatomie, Vol 5. Gebrüder Borntraeger, eds W. Zimmermann, P. Ozenda, and H. D. Wulff (Berlin: John Wiley \& Sons Inc.), 154-163.

Fernandez, L., Torregrosa, L., Segura, V., Bouquet, A., and Martinez-Zapater, J. M. (2010). Transposon-induced gene activation as a mechanism generating cluster shape somatic variation in grapevine. Plant J. 61, 545-557. doi: 10.1111/j.1365313X.2009.04090.x

Garner, W. W., and Allard, H. A. (1920). Effect of the relative length of day and night and other factors of the environment on growth and reproduction in plants. $J$ Agric. Res. 18, 553-606.

Granovsky, A. E., and Rosner, M. R. (2008). Raf kinase inhibitory protein: a signal transduction modulator and metastasis suppressor. Cell Res. 18, 452-457. doi: $10.1038 / \mathrm{cr} .2008 .43$

Hallé, F., Oldeman, R. A., and Tomlinson, P. B. (1978). Tropical Trees and Forests Berlin: Springer. doi: 10.1007/978-3-642-81190-6

Hanzawa, Y., Money, T., and Bradley, D. (2005). A single amino acid converts a repressor to an activator of flowering. Proc. Natl. Acad. Sci. U.S.A. 102, 7748-7753. doi: 10.1073/pnas.0500932102

Hareven, D., Gutfinger, T., Parnis, A., Eshed, Y., and Lifschitz, E. (1996). The making of a compound leaf: genetic manipulation of leaf architecture in tomato. Cell 84, 735-744. doi: 10.1016/S0092-8674(00)81051-X

Hayama, R., Agashe, B., Luley, E., King, R., and Coupland, G. (2007). A circadian rhythm set by dusk determines the expression of FT homologs and the short-day photoperiodic flowering response in Pharbitis. Plant Cell 19, 2988-3000. doi: 10.1105/tpc.107.052480

Hayama, R., Yokoi, S., Tamaki, S., Yano, M., and Shimamoto, K. (2003). Adaptation of photoperiodic control pathways produces short-day flowering in rice. Nature 422, 719-722. doi: 10.1038/nature01549

Hecht, V., Laurie, R. E., Vander Schoor, J. K., Ridge, S., Knowles, C. L., Liew, L. C., et al. (2011). The pea GIGAS gene is a FLOWERING LOCUS T homolog necessary for graft-transmissible specification of flowering but not for responsiveness to photoperiod. Plant Cell 23, 147-161. doi: 10.1105/tpc.110 081042

Higuchi, Y., Narumi, T., Oda, A., Nakano, Y., Sumitomo, K., Fukai, S., et al. (2013). The gated induction system of a systemic floral inhibitor, antiflorigen, determines obligate short-day flowering in Chrysanthemums. Proc. Natl. Acad. Sci. U.S.A. 110, 17137-17142. doi: 10.1073/pnas.1307617110

Hiraoka, K., Yamaguchi, A., Abe, M., and Araki, T. (2013). The florigen genes FT and TSF modulate lateral shoot outgrowth in Arabidopsis thaliana. Plant Cell Physiol. 54, 352-368. doi: 10.1093/pcp/pcs168

Ho, W. W., and Weigel, D. (2014). Structural features determining flower-promoting activity of Arabidopsis FLOWERING LOCUS T. Plant Cell 26, 552-564. doi: 10.1105/tpc.113.115220

Hsu, C. Y., Adams, J. P., Kim, H., No, K., Ma, C., Strauss, S. H., et al. (2011). FLOWERING LOCUS $\mathrm{T}$ duplication coordinates reproductive and vegetative growth in perennial poplar. Proc. Natl. Acad. Sci. U.S.A. 108, 10756-10761. doi: 10.1073/pnas.1104713108

Iwata, H., Gaston, A., Remay, A., Thouroude, T., Jeauffre, J., Kawamura, K., et al. (2012). The TFL1 homologue KSN is a regulator of continuous flowering in rose and strawberry. Plant J. 69, 116-125. doi: 10.1111/j.1365-313X.2011. 04776.x

Jaeger, K. E., Pullen, N., Lamzin, S., Morris, R. J., and Wigge, P. A. (2013). Interlocking feedback loops govern the dynamic behavior of the floral transition in Arabidopsis. Plant Cell 25, 820-833. doi: 10.1105/tpc.113.109355

Jiang, K., Liberatore, K. L., Park, S. J., Alvarez, J. P., and Lippman, Z. B. (2013). Tomato yield heterosis is triggered by a dosage sensitivity of the florigen pathway that fine-tunes shoot architecture. PLoS Genet. 9:e1004043. doi: 10.1371/journal.pgen.1004043

Kardailsky, I., Shukla, V. K., Ahn, J. H., Dagenais, N., Christensen, S. K., Nguyen, J. T., et al. (1999). Activation tagging of the floral inducer FT. Science 286, 1962-1965. doi: $10.1126 /$ science.286.5446.1962

Karlgren, A., Gyllenstrand, N., Clapham, D., and Lagercrantz, U. (2013). FLOWERING LOCUS T/TERMINAL FLOWER1-like genes affect growth rhythm and bud set in Norway spruce. Plant Physiol. 163, 792-803 doi: 10.1104/pp.113. 224139

Karlgren, A., Gyllenstrand, N., Källman, T., Sundström, J. F., Moore, D., Lascoux, M., et al. (2011). Evolution of the PEBP gene family in plants: functional diversification in seed plant evolution. Plant Physiol. 156, 1967-1977. doi: 10.1104/pp.111.176206

Kinet, J. M. (1977). Effect of light conditions on the development of the inflorescence in tomato. Sci. Hortic. 6, 15-26. doi: 10.1016/0304-4238(77)90074-7

Klintenäs, M., Pin, P. A., Benlloch, R., Ingvarsson, P. K., and Nilsson, O. (2012). Analysis of conifer FLOWERING LOCUS T/TERMINAL FLOWER1-like genes provides evidence for dramatic biochemical evolution in the angiosperm FT lineage. New Phytol. 196, 1260-1273. doi: 10.1111/j.1469-8137.2012.04332.x

Kloosterman, B., Abelenda, J. A., Gomez Mdel, M., Oortwijn, M., de Boer, J. M., Kowitwanich, K., et al. (2013). Naturally occurring allele diversity allows potato cultivation in northern latitudes. Nature 495, 246-250. doi: 10.1038/nature11912

Kobayashi, Y., Kaya, H., Goto, K., Iwabuchi, M., and Araki, T. (1999). A pair of related genes with antagonistic roles in mediating flowering signals. Science 286, 1960-1962. doi: 10.1126/science.286.5446.1960

Kobayashi, Y., and Weigel, D. (2007). Move on up, it's time for change - mobile signals controlling photoperiod-dependent flowering. Genes Dev. 21, 2371-2384. doi: 10.1101/gad.1589007

Kojima, S., Takahashi, Y., Kobayashi, Y., Monna, L., Sasaki, T., Araki, T., et al. (2002). Hd3a, a rice ortholog of the Arabidopsis FT gene, promotes transition to flowering downstream of Hd1 under short-day conditions. Plant Cell Physiol. 43, 1096-1105. doi: 10.1093/pcp/pcf156

Koornneef, M., Hanhart, C. J., and van der Veen, J. H. (1991). A genetic and physiological analysis of late flowering mutants in Arabidopsis thaliana. Mol. Gen. Genet. 229, 57-66. doi: 10.1007/BF00264213

Krieger, U., Lippman, Z. B., and Zamir, D. (2010). The flowering gene SINGLE FLOWER TRUSS drives heterosis for yield in tomato. Nat. Genet. 42, 459-463. doi: 10.1038/ng.550

Kumar, S. V., Lucyshyn, D., Jaeger, K. E., Alós, E., Alvey, E., Harberd, N. P., et al. (2012). Transcription factor PIF4 controls the thermosensory activation of flowering. Nature 484, 242-245. doi: 10.1038/nature10928

Kumimoto, R. W., Adam, L., Hymus, G. J., Repetti, P. P., Reuber, T. L., Marion, C. M., et al. (2008). The Nuclear Factor Y subunits NF-YB2 and NF-YB3 play additive roles in the promotion of flowering by inductive long-day photoperiods in Arabidopsis. Planta 228, 709-723. doi: 10.1007/s00425-008-0773-6

Kurokura, T., Mimida, N., Battey, N. H., and Hytönen, T. (2013). The regulation of seasonal flowering in the Rosaceae. J. Exp. Bot. 64, 4131-4141. doi: $10.1093 /$ jxb/ert233

Kwak, M., Velasco, D., and Gepts, P. (2008). Mapping homologous sequences for determinacy and photoperiod sensitivity in common bean (Phaseolus vulgaris) J. Hered. 99, 283-291. doi: 10.1093/jhered/esn005

Lang, A., Chilakhian, M. K., and Frolova, L. A. (1977). Promotion and inhibition of flower formation in a day-neutral plant in graft with a short-day plant and a longday plant. Proc. Natl. Acad. Sci. U.S.A. 74, 2412-2416. doi: 10.1073/pnas.74.6.2412

Lee, R., Baldwin, S., Kenel, F., McCallum, J., and Macknight, R. (2013). FLOWERING LOCUS T genes control onion bulb formation and flowering. Nat. Commun. 4:2884. doi: $10.1038 /$ ncomms 3884 
Leopold, A. C., and Lam, S. L. (1960). A leaf factor influencing tomato flowering. Proc. Am. Soc. Hort. Sci. 76, 543-547.

Li, D., Liu, C., Shen, L., Wu, Y., Chen, H., Robertson, M., et al. (2008). A repressor complex governs the integration of flowering signals in Arabidopsis. Dev. Cell 15, 110-120. doi: 10.1016/j.devcel.2008.05.002

Lifschitz, E., and Eshed, Y. (2006). Universal florigenic signals triggered by FT homologues regulate growth and flowering cycles in perennial day-neutral tomato. $J$. Exp. Bot. 57, 3405-3414. doi: 10.1093/jxb/erl106

Lifschitz, E., Eviatar, T., Rozman, A., Shalit, A., Goldshmidt, A., Amsellem, Z., et al. (2006). The tomato FT ortholog triggers systemic signals that regulate growth and flowering and substitute for diverse environmental stimuli. Proc. Natl. Acad. Sci. U.S.A. 103, 6398-6403. doi: 10.1073/pnas.0601620103

Liljegren, S. J., Gustafson-Brown, C., Pinyopich, A., Ditta, G. S., and Yanofsky, M. F. (1999). Interactions among APETALA1, LEAFY, and TERMINAL FLOWER1 specify meristem fate. Plant Cell 11, 1007-1018. doi: 10.1105/tpc.11. 6.1007

Lin, M. K., Belanger, H., Lee, Y. J., Varkonyi-Gasic, E., Taoka, K., Miura, E., et al. (2007). FLOWERING LOCUS T protein may act as the long-distance florigenic signal in the Cucurbits. Plant Cell 19, 1488-1506. doi: 10.1105/tpc.107.051920

Lippman, Z. B., Cohen, O., Alvarez, J. P., Abu-Abied, M., Pekker, I., Paran, I., et al. (2008). The making of a compound inflorescence in tomato and related nightshades. PLoS Biol. 6:e288. doi: 10.1371/journal.pbio.0060288

Liu, L., Liu, C., Hou, X., Xi, W., Shen, L., Tao, Z., et al. (2012). FTIP1 is an essential regulator required for florigen transport. PLoS Biol. 10:e1001313. doi: 10.1371/journal.pbio. 1001313

Lowry, D. B., and Willis, J. H. (2010). A widespread chromosomal inversion polymorphism contributes to a major life-history transition, local adaptation, and reproductive isolation. PLoS Biol. 8:e1000500. doi: 10.1371/journal.pbio. 1000500

MacArthur, J. W. (1932). Inherited characters in the tomato. I. The self pruning habit. J. Hered. 23, 395-396.

Mathieu, J., Warthmann, N., Küttner, F., and Schmid, M. (2007). Export of FT protein from phloem companion cells is sufficient for floral induction in Arabidopsis. Curr. Biol. 17, 1055-1060. doi: 10.1016/j.cub.2007.05.009

Mathieu, J., Yant, L. J., Mürdter, F., Küttner, F., and Schmid, M. (2009). Repression of flowering by the miR172 target SMZ. PLoS Biol. 7:e1000148. doi 10.1371/journal.pbio. 1000148

Mauney, J. R., and Ball, E. (1959). The axillary buds of Gossypium. Bull. Torrey Bot Club 856, 236-244. doi: 10.2307/2482840

McGarry, R. C., and Ayre, B. G. (2012a). Geminivirus-mediated delivery of florigen promotes determinate growth in aerial organs and uncouples flowering from photoperiod in cotton. PLoS ONE 7:e36746. doi: 10.1371/journal.pone. 0036746

McGarry, R. C., and Ayre, B. G. (2012b). Manipulating plant architecture with members of the CETS gene family. Plant Sci. 188-189, 71-81. doi: 10.1016/j.plantsci.2012.03.002

McGarry, R. C., and Ayre, B. G. (2012c). "Florigen and cotton: manipulating plant architecture to improve plant productivity," in Flowering and Fruiting in Cotton, ed. D. M. Oosterhuis (New York: Springer).

Meng, X., Muszynski, M. G., and Danilevskaya, O. N. (2011). The FT-like ZCN8 gene functions as a floral activator and is involved in photoperiod sensitivity in maize. Plant Cell 23, 942-960. doi: 10.1105/tpc.110.081406

Meyerowitz, E. M. (1989). Arabidopsis, a useful weed. Cell 56, 263-269. doi: 10.1016/0092-8674(89)90900-8

Mizoguchi, T., Wright, L., Fujiwara, S., Cremer, F., Lee, K., Onouchi, H., et al. (2005). Distinct roles of GIGANTEA in promoting flowering and regulating circadian rhythms in Arabidopsis. Plant Cell 17, 2255-2270. doi: 10.1105/tpc.105. 033464

Molinero-Rosales, N., Latorre, A., Jamilena, M., and Lozano, R. (2004). SINGLE FLOWER TRUSS regulates the transition and maintenance of flowering in tomato. Planta 218, 427-434. doi: 10.1007/s00425-003-1109-1

Nakamura, Y., Andrés, F., Kanehara, K., Liu, Y. C., Dörmann, P., and Coupland, G. (2014). Arabidopsis florigen FT binds to diurnally oscillating phospholipids that accelerate flowering. Nat. Commun. 5:3553. doi: 10.1038/ncomms4553

Navarro, C., Abelenda, J. A., Cruz-Oro, E., Cuellar, C. A., Tamaki, S., Silva, J., et al. (2011). Control of flowering and storage organ formation in potato by FLOWERING LOCUS T. Nature 478, 119-122. doi: 10.1038/nature10431

Naz, A. A., Raman, S., Martinez, C. C., Sinha, N. R., Schmitz, G., and Theres, K. (2013). Trifoliate encodes an MYB transcription factor that modulates leaf and shoot architecture in tomato. Proc. Natl. Acad. Sci. U.S.A. 110, 2401-2406. doi: 10.1073/pnas.1214300110

Ogiso-Tanaka, E., Matsubara, K., Yamamoto, S., Nonoue, Y., Wu, J., Fujisawa, H., etal. (2013). Natural variation of the RICE FLOWERING LOCUS T 1 contributes to flowering time divergence in rice. PLoS ONE 8:e75959. doi: 10.1371/journal.pone.0075959

Ori, N., Cohen, A. R., Etzioni, A., Brand, A., Yanai, O., Shleizer, S., et al. (2007). Regulation of LANCEOLATE by miR319 is required for compound-leaf development in tomato. Nat. Genet. 39, 787-791. doi: 10.1038/ng2036

Osmani, A., Pu, R. T., and Morris, N. (1988). Mitotic induction and maintenance by overexpression of a G2-specific gene that encodes a potential protein kinase. Cell 53, 237-244. doi: 10.1016/0092-8674(88)90385-6

Park, S. J., Eshed, Y., and Lippman, Z. B. (2014). Meristem maturation and inflorescence architecture - lessons from the Solanaceae. Curr. Opin. Plant Biol. 17, 70-77. doi: 10.1016/j.pbi.2013.11.006

Périlleux, C., Lobet, G., and Tocquin, P. (2014). Inflorescence development in tomato: gene functions within a zigzag model. Front. Plant Sci. 5:121. doi: 10.3389/fpls.2014.00121

Pin, P. A., Benlloch, R., Bonnet, D., Wremerth-Weich, E., Kraft, T., Gielen, J. J. L., et al. (2010). An antagonistic pair of FT homologs mediates the control of flowering time in sugar beet. Science 330, 1397-1400. doi: 10.1126/science. 1197004

Pnueli, L., Carmel-Goren, L., Hareven, D., Gutfinger, T., Alvarez, J., Ganal, M., et al. (1998). The SELF-PRUNING gene of tomato regulates vegetative to reproductive switching of sympodial meristems and is the ortholog of CEN and TFL1. Development 125, 1979-1989.

Pnueli, L., Gutfinger, T., Hareven, D., Ben-Naim, O., Ron, N., Adir, N., et al. (2001). Tomato SP-interacting proteins define a conserved signaling system that regulates shoot architecture and flowering. Plant Cell 13, 2687-2702. doi: 10.1105/tpc.13.12.2687

Putterill, J., Laurie, R., and Macknight, R. (2004). It's time to flower: the genetic control of flowering time. Bioessays 26, 363-373. doi: 10.1002/bies.20021

Putterill, J., Robson, F., Lee, K., Simon, R., and Coupland, G. (1995). The CONSTANS gene of Arabidopsis promotes flowering and encodes a protein showing similarities to zinc finger transcription factors. Cell 80, 847-857. doi: 10.1016/0092-8674(95)90288-0

Ratcliffe, O. J., Amaya, I., Vincent, C. A., Rothstein, S., Carpenter, R., Coen, E. S., et al. (1998). A common mechanism controls the life cycle and architecture of plants. Development 125, 1609-1615.

Ratcliffe, O. J., Bradley, D. J., and Coen, E. S. (1999). Separation of shoot and floral identity in Arabidopsis. Development 126, 1109-1120.

Rick, C. M. (1978). The tomato. Sci. Am. 239, 76-87. doi: 10.1038/scientificamerican0878-76

Ruiz-García, L., Madueño, F., Wilkinson, M., Haughn, G., Salinas, J., and Martínez-Zapater, J. M. (1997). Different roles of flowering-time genes in the activation of floral initiation genes in Arabidopsis. Plant Cell 9, 1921-1934. doi: 10.1105/tpc.9.11.1921

Samach, A., Onouchi, H., Gold, S. E., Ditta, G. S., Schwarz-Sommer, Z., Yanofsky, M. F., etal. (2000). Distinct roles of CONSTANS target genes in reproductive development of Arabidopsis. Science 288, 1613-1616. doi: $10.1126 /$ science. 288.5471 .1613

Schmid, M., Uhlenhaut, N. H., Godard, F., Demar, M., Bressan, R., Weigel, D., et al. (2003). Dissection of floral induction pathways using global expression analysis. Development 130, 6001-6012. doi: 10.1242/dev.00842

Schoentgen, F., Saccoccio, F., Jolles, J., Bernier, I., and Jolles, P. (1987). Complete amino acid sequence of a basic $21-\mathrm{kDa}$ protein from bovine brain cytosol. Eur. J. Biochem. 166, 333-338. doi: 10.1111/j.1432-1033.1987. tb13519.x

Serre, L., Vallee, B., Bureaud, N., Schoentgen, F., and Zelwer, C. (1998). Crystal sturucture of the phosphatidylethanolamine-binding protein from bovine: a novel structural class of phospholipid-binding proteins. Structure 6, 1255-1265. doi: 10.1016/S0969-2126(98)00126-9

Simpson, G. G., and Dean, C. (2002). Arabidopsis, the Rosetta stone of flowering time? Science 296, 285-289. doi: 10.1126/science.296.5566.285

Shalit, A., Rozman, A., Goldshmidt, A., Alvarez, J. P., Bowman, J. L., Eshed, Y., et al. (2009). The flowering hormone florigen functions as a general systemic regulator of growth and termination. Proc. Natl. Acad. Sci. U.S.A. 106, 8392-8397. doi: 10.1073/pnas.0810810106 
Shannon, S., and Meeks-Wagner, D. R. (1991). A mutation in the Arabidopsis TFL1 gene affects inflorescence meristem development. Plant Cell 3, 877-892. doi: 10.1105/tpc.3.9.877

Sohn, E. J., Rojas-Pierce, M., Pan, S., Carter, C., Serrano-Mislata, A., Madueño, F., et al. (2007). The shoot meristem identity gene TFL1 is involved in flower development and trafficking to the protein storage vacuole. Proc. Natl. Acad. Sci. U.S.A. 104, 18801-18806. doi: 10.1073/pnas.0708236104

Sparks, E., Wachsman, G., and Benfey, P. N. (2013). Spatiotemporal signalling in plant development. Nat. Rev. Genet. 14, 631-644. doi: 10.1038/nrg3541

Suarez-Lopez, P., Wheatley, K., Robson, F., Onouchi, H., Valverde, F., and Coupland, G. (2001). CONSTANS mediates between the circadian clock and the control of flowering in Arabidopsis. Nature 410, 1116-1120. doi: 10.1038/35074138

Szymkowiak, E. J., and Irish, E. E. (2006). JOINTLESS suppresses sympodial identity in inflorescence meristems of tomato. Planta 223, 646-658. doi: 10.1007/s00425005-0115-x

Tamaki, S., Matsuo, S., Wong, H. L., Yokoi, S., and Shimamoto, K. (2007). $\mathrm{Hd} 3$ a protein is a mobile flowering signal in rice. Science 316, 1033-1036. doi: $10.1126 /$ science. 1141753

Taoka, K., Ohki, I., Tsuji, H., Furuita, K., Hayashi, K., Yanase, T., et al. (2011). 14-3-3 proteins act as intracellular receptors for rice Hd3a florigen. Nature 476, 332-335. doi: $10.1038 /$ nature 10272

Tian, Z., Wang, X., Lee, R., Li, Y., Specht, J. E., Nelson, R. L., et al. (2010). Artificial selection for determinate growth habit in soybean. Proc. Natl. Acad. Sci. U.S.A. 107, 8563-8568. doi: 10.1073/pnas.1000088107

Torti, S., Fornara, F., Vincent, C., Andrés, F., Nordström, K., Göbel, U., et al. (2012). Analysis of the Arabidopsis shoot meristem transcriptome during floral transition identifies distinct regulatory patterns and a leucine-rich repeat protein that promotes flowering. Plant Cell 24, 444-462. doi: 10.1105/tpc.111.092791

Turck, F., Fornara, F., and Coupland, G. (2008). Regulation and identity of florigen: FLOWERING LOCUS T moves center stage. Annu. Rev. Plant Biol. 59, 573-594. doi: 10.1146/annurev.arplant.59.032607.092755

Turck, F., Roudier, F., Farrona, S., Martin-Magniette, M. L., Guillaume, E., Buisine, N., et al. (2007). Arabidopsis TFL2/LHP1 specifically associates with genes marked by trimethylation of histone $\mathrm{H} 3$ lysine 27. PLoS Genet. 3:e86. doi: 10.1371/journal.pgen.0030086

Turnbull, C. (2011). Long-distance regulation of flowering time. J. Exp. Bot. 62, 4399-4413. doi: 10.1093/jxb/err191

Wang, R., Albani, M. C., Vincent, C., Bergonzi, S., Luan, M., Bai, Y., et al. (2011). Aa TFL1 confers an age-dependent response to vernalization in perennial Arabis alpina. Plant Cell 23, 1307-1321. doi: 10.1105/tpc.111.83451

Wenkel, S., Turck, F., Singer, K., Gissot, L., Le Gourrierec, J., Samach, A., et al. (2006). CONSTANS and the CCAAT box binding complex share a functionally important domain and interact to regulate flowering of Arabidopsis. Plant Cell 18, 2971-2984. doi: 10.1105/tpc.106.043299
Wigge, P. A., Kim, M. C., Jaeger, K. E., Busch, W., Schmid, M., Lohmann, J. U., et al. (2005). Integration of spatial and temporal information during floral induction in Arabidopsis. Science 309, 1056-1059. doi: 10.1126/science.1114358

Yamaguchi, A., Kobayashi, Y., Goto, K., Abe, M., and Araki, T. (2005). TWIN SISTER OF FT (TSF) acts as a floral pathway integrator redundantly with FT. Plant Cell Physiol. 46, 1175-1189. doi: 10.1093/pcp/pci151

Yamaguchi, A., Wu, M. F., Yang, L., Wu, G., Poethig, R. S., and Wagner, D. (2009). The microRNA-regulated SBP-Box transcription factor SPL3 is a direct upstream activator of LEAFY, FRUITFULL, and APETALA1. Dev. Cell 17, 268-278. doi: 10.1016/j.devcel.2009.06.007

Yang, Y., Klejnot, J., Yu, X., Liu, X., and Lin, C. (2007). Florigen (II): it is a mobile protein. J. Integr. Plant Biol. 49, 1665-1669. doi: 10.1111/j.1744-7909.2007.00614.x

Yeager, A. F. (1927). Determinate growth in the tomato. J. Hered. 18, 263-265.

Yeung, K., Seitz, T., Li, S., Janosch, P., McFerran, B., Kaiser, C., et al. (1999). Suppression of Raf-1 kinase activity and MAP kinase signaling by RKIP. Nature 401, 173-177. doi: 10.1038/43686

Yoo, S. C., Chen, C., Rojas, M., Daimon, Y., Ham, B. K., Araki, T., et al. (2013). Phloem long-distance delivery of FLOWERING LOCUS T (FT) to the apex. Plant J. 75, 456-468. doi: 10.1111/tpj.12213

Zeevaart, J. A. (1962). Physiology of flowering: flowering is hormonally controlled, but the nature of the hormone remains to be elucidated. Science 137, 723-731. doi: 10.1126/science.137.3532.723

Zeevaart, J.A. (2006). Florigen coming of age after 70 years. Plant Cell 18, 1783-1789. doi: $10.1105 /$ tpc.106.043513

Zeevaart, J. A. D. (1976). Physiology of flower formation. Annu. Rev. Plant Physiol. 27, 321-348. doi: 10.1146/annurev.pp.27.060176.001541

Conflict of Interest Statement: The authors declare that the research was conducted in the absence of any commercial or financial relationships that could be construed as a potential conflict of interest.

Received: 17 June 2014; accepted: 27 August 2014; published online: 16 September 2014.

Citation: Lifschitz E, Ayre BG and Eshed Y (2014) Florigen and anti-florigen - a systemic mechanism for coordinating growth and termination in flowering plants. Front. Plant Sci. 5:465. doi: 10.3389/fpls.2014.00465

This article was submitted to Plant Genetics and Genomics, a section of the journal Frontiers in Plant Science.

Copyright (C) 2014 Lifschitz, Ayre and Eshed. This is an open-access article distributed under the terms of the Creative Commons Attribution License (CC BY). The use, distribution or reproduction in other forums is permitted, provided the original author(s) or licensor are credited and that the original publication in this journal is cited, in accordance with accepted academic practice. No use, distribution or reproduction is permitted which does not comply with these terms. 